\title{
G

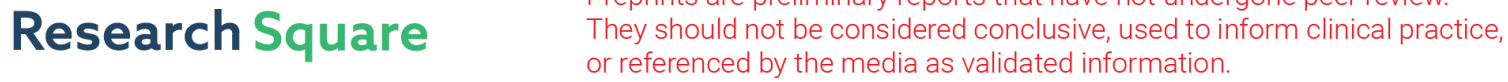 \\ Reproductive Behavior of Different Species of the Genus Ovis (Ovis Linnaeus, 1758) During Hybridization
}

\section{Baylar lolchiev ( $\sim$ baylar1@yandex.ru )}

L.K Ernst Federal Science Center for Animal Husbandry: FGBNU Federal'nyj naucnyj centr zivotnovodstva-VIZ imeni akademika L K Ernsta https://orcid.org/0000-0001-5386-7263 Neilia Khusnetdinova

L.K Ernst Federal Science Center for Animal Husbandry: FGBNU Federal'nyj naucnyj centr zivotnovodstva-VIZ imeni akademika L K Ernsta

\section{Prytkov Yuri}

L.K Ernst Federal Science Center for Animal Husbandry: FGBNU Federal'nyj naucnyj centr zivotnovodstva-VIZ imeni akademika L K Ernsta

\section{Vugar Bagirov}

L.K Ernst Federal Science Center for Animal Husbandry: FGBNU Federal'nyj naucnyj centr zivotnovodstva-VIZ imeni akademika L K Ernsta

\section{Natalya Volkova}

L.K Ernst Federal Science Center for Animal Husbandry: FGBNU Federal'nyj naucnyj centr zivotnovodstva-VIZ imeni akademika L K Ernsta

\section{Research}

Keywords: reproductive behavior, mating system, sheep, hybrid, mouflon

Posted Date: May 20th, 2021

DOl: https://doi.org/10.21203/rs.3.rs-516736/v1

License: (c) (1) This work is licensed under a Creative Commons Attribution 4.0 International License. Read Full License 


\section{Abstract}

\section{Background}

There are several mechanisms of species isolation and species conservation, one of which is the behavior of individuals during the mating season. Inter specific hybridization is used to create new breeding forms and breeds of farm animals. The aim of this study was to look into the reproductive behavior of males of cultured sheep breeds and their wild relatives during the mating period in order to identify consistent patterns of movements, elementary motor acts, and individual reactions.

\section{Results}

It was found that the duration of the courtship display in the European mouflon was, with a high degree of confidence, longer than in the male domestic sheep. In mouflons, it was $246.5 \pm 31.85$ minutes, while in rams, it was $88.46 \pm 9.23$ minutes $(p<0.0001)$. Many patterns in purebred sheep were shorter, or absent. In wild species, there is a connection between sexual activity and time of day. The highest frequency of intromission in mouflons occurred in the time interval between 6-8 a.m. and 11 p.m. -4 a.m.; in rams, the dependence of sexual activity on the time of day was not observed. During the estrus period, the relationship between females changed. If there were several individuals in the group in the state of estrus at the same time, the dominant females hindered the reproductive success of the lowerranking sheep.

\section{Conclusions}

The present study shows that the patterns of reproductive behavior in males of different species of sheep are similar. However, it was revealed that the species differ in the length of those patterns. A high variability in the strategies of sheep reproduction was observed. For future research, it would be beneficial to focus on the features of the reproductive behavior of female sheep depending on the genotype.

\section{Introduction}

The reproductive behavior of animals plays an important role in reproduction, affecting both the success of mating and the survival of the offspring $[1,2,3]$. Various patterns of sexual behavior have been described for many animals, such as mammals [4, 5, 6] and livestock [7]. All patterns of sexual behavior arise in the course of evolution; they are influenced by genetic, physiological, and environmental factors, as well as previous individual experiences. Despite the availability of studies describing the diverse mating systems in many animals, only a few articles are devoted to the assessment of the reproductive behavior of wild and domestic sheep during interspecific hybridization. There are isolated works focusing on Ovis canadensis [8] and Ovis orientalislaristanika [9] in the wild. The data are insufficient, as they are largely based on random observations. Scientific data on the breed-dependent reproductive behaviors of sheep are limited. The available literature describes the comparative characteristics of the sexual activity of rams of the Finnish Landrace and Suffolk breeds; the males of the Finnish Landrace breed are more 
active than the rams of the Suffolk breed [10]. The results of a study performed by other authors who looked into the behavior of rams of the Suffolk, Dorper, and Texel breeds showed that the rams of the Suffolk breed are more active than those of the Dorper and Texel breeds [11].

In the wild, bovid animals are promiscuous, and during the breeding season, they try to mate with as many females as possible [12]; that is, most males are characterized by a polygynous breeding system, where a male gathers a harem of up to several dozen females and protects them from other males. For some sheep (Santa Cruz, Soy), promiscuity has also been reported [13].

The sexual activity of females is characterized by the periodic manifestation of a complex of interrelated physiological processes. The length of the sexual cycle in ewes varies from 13 to 21 days. [14]. The release of the luteinizing hormone into the blood and ovulation in females occur before mating.

Sexual behavior is one of the mechanisms of species conservation and species isolation, which is aimed at the prevention of the destruction of the identity of a species. The mechanism of the genetic isolation of a species is very complex. There are numerous and often contradictory opinions on this issue. Species isolation includes various forms of incompatibility; for example, differences in chromosome sets, mismatch of ecological niches, mating periods, geographical and ecological isolation, etc. One of the main barriers to uncontrolled interspecific mating in the wild is the behavioral response of individuals. Each species has its own behavioral feature during the breeding season. During the mating season, females and males attract the opposite sex in various ways, that is, they send signals that are understood by individuals of the same species, while other species simply do not notice them. The behavior of some hybrids during the mating season is often abnormal for particular species.

Interspecific hybridization occurs both in the wild and in agriculture. Fundamental and practical experimental studies on the hybridization of domestic sheep with wild representatives of the genus Ovis have been carried out [15]. In this regard, the study of the sexual behavior of individuals of different genotypes is of scientific interest and can be used for the conservation of species and breeding of interspecific hybrids. The aim of the present study was to compare the reproductive behavior of males of cultured sheep breeds and their wild relatives in order to identify consistent patterns of movements, elementary motor acts, and individual reactions.

\section{Materials And Methods}

\subsection{Animals}

A domestic sheep (Ovis aries)

This research was carried out at the experimental farm of the Federal Research Center for Animal Husbandry named after L. K. Ernst. A total of 90 ewe and 6 rams of the Katahdin breed were included in the experiment. Before setting up the experiment, all animals were clinically examined. All animals were clinically healthy and were under veterinary supervision. The animals were kept in groups in a paddock on 
a straw mat under a canopy; the size of the paddock was $1.5 \mathrm{~m} 2$ per sheep and $2 \mathrm{~m} 2$ per ram. The sheep had free access to food and clean water. The ages of the ewes were 18-48 months, with an average of $34 \pm 3.7$ months; their live weights varied from 50 to $80 \mathrm{~kg}$, with an average of $63.7 \pm 3.6 \mathrm{~kg}$. All of the animals were sexually mature. The ages of the rams varied from 24 to 56 months, with an average of 42 \pm 4.5 months. The live weights of the rams varied from 65 to $80 \mathrm{~kg}$, with an average of $71.9 \pm 2.08 \mathrm{~kg}$. The rams for the experiment were selected according to reproductive parameters; clinical studies of the reproductive organs and sperm quality control were carried out. The semen quality of the brood rams was evaluated by using the CASA technology.

European mouflon (Ovis gmelini musimon)

The mouflons were obtained from the nursery at the age of 12 months. From the age of 12 months, they were kept in an experimental center. At the beginning of the experiment, the mouflons were 48 and 57 months old. From December 25 to November 15, the mouflons were kept in separate enclosures with dimensions of $4 \times 3 \mathrm{~m}$. During the breeding season, the mouflons were kept together with the ewe. The live weights of the mouflons were 60 and $68 \mathrm{~kg}$.

\subsection{Mating scheme}

The breeding season in the region where the study was performed fell in September and December. Before the group was formed in October, the ewes were kept in herds on pasture, while the rams were kept in separate pens. In November, 6 groups of ewe were formed for mating, with a female/male ratio of 15:1. The experiment lasted from November 15 to December 30. In all groups, the estrus of the ewe was natural.

\subsection{Data collection}

The experiments were recorded with a KERUI 6 MP digital video camera. The resulting video material was processed in the "MovaviVideoEditor" computer program, a professional system for collecting and analyzing data using video files. The timing and reaction time were recorded during the observations. The courtship display was calculated and described, consisting of the desire to approach the opposite sex, sniffing, circular movement (when the male and female moved in circles simultaneously), rubbing the muzzle, putting the head on the back of the female, the flehmen response (when a male curls back its upper lip after sniffing the female's genitourinary area or her urine), intromission, and ejaculation. In total, 504 hours of video data were processed and viewed, and 118 images of various alterations of sexual behavior were obtained.

\subsection{Statistical analysis}

The digital data obtained in the experiment were biometrically processed using the "GraphPadPrism v.8" program. The samples were tested for the normality of the distribution according to the Shapiro-Wilk test. The hypotheses were tested using a single-factor analysis of variance and a t-test, if necessary. A 
value of $p<0.05$ was considered statistically significant. All results are presented as the mean and the standard error of the mean.

\section{Results}

\subsection{Sexual behavior of rams}

In the case of interaction between a ewe and a ram, a complex of interrelated physiological responses of the male to the females was recorded. The data are shown in Table 1. In the European mouflon, the "follow" reaction appeared first; then, the male began its courtship-a typical orientation of the ram behind the ewe: Its body was headed in the same direction as that of the ewe. As a rule, the right or left shoulder of the male mouflon touched the left or right side of the ewe, respectively, followed by sniffing the body of the ewe (at this point, the male could sometimes "bite" the female); the forelimb stretched and then bent; at the same time, the ram tilted its head, then either kicked or pushed its muzzle to the inguinal area of the ewe, which stimulated the ewe to urinate; at this point, the female often moved her tail from side to side (Fig. 1). It can be stated with high confidence that the duration of the courtship display in the European mouflon was longer than in the bred Katahdin $(246.5 \pm 31.85 ; 88.46 \pm 9.23 ; p<$ 0.0001 ) (Fig. 2). Many patterns in bred Katahdin were shorter or absent. As the ewe urinated, the ram showed the flehmen reaction. The flehmen reaction is tied to the detection of pheromones by the vomeronasal organ. The flehmen reaction occurs several times before the act of mating itself. During the flehmen response, the ram's head is raised 40-50 degrees, the nostrils are pulled back, and the upper lip is bent caudally, revealing the toothless part of the upper jaw. The flehmen reaction can last from a few seconds to 1 minute. On average, in purebred males, the flehmen reaction lasts $45.93 \pm 4.08 \mathrm{~s}$; in the European mouflon, it is $40.14 \pm 4.12 \mathrm{~s}$. No significant differences were found between these groups ( $p=$ 0.3279). In the case of the ewe's positive behavioral reaction, further acts happened, where the ram embraced the back of the ewe with its forelimbs or put its front legs on the sheep; then, an erection occurred, accompanied by fluctuations in the ram's pelvis. The sexual behavior of the European mouflon was more stereotypical. Usually, the male made several (1-2) long mounts with intromission, followed by ejaculation. The ejaculation was accompanied by a deep push forward; then, the ram dismounted.

The length of the intromission in the European mouflon was $15.33 \pm 1.1 \mathrm{~s}$ on average (Fig. 3). In purebred Katahdins, the whole sexual behavior complex was more rhythmic. The male made several short intromissions $(2.3 \pm 0.1 \mathrm{~s})$, and within an hour of observation, the total number of intromissions on one ewe could reach 10-12, and then the partners lost interest (Table 1). On the first day of placing males with females, that is, after a long sexual rest, purebred Katahdins could copulate up to 40 times, and European mouflons could do so up to 20 times, but in both cases, the frequency decreased significantly on subsequent days. There was a significant difference in the length of predominance of sexual behavior in the European mouflon and pure-bred males of the Katahdin breed during the day. In Katahdin rams, we did not observe a relationship between the time of day and sexual activity. In mouflons, this relationship was observed. The greatest number of intromissions in mouflons was observed between 6-8 a.m. and 11 p.m. -4 a.m. (Fig. 4). In the daytime and in the evening (from 8 a.m. to 11 p.m.), the European 
mouflons performed single rolls and intromissions. During this time of day, the European mouflons exhibited sniffing and following. The European mouflon exhibited behaviors that were different from those of the Katadin rams; the mouflons used the "running" tactic, in which the ram chased the sheep and tried to mate, as well as the blocking tactic, in which the male restricted the sheep's movement, blocking its attempts to leave the territory.

Table 1

Length of some elements of sexual behavior in males of the Ovis Linnaeus genus.

\begin{tabular}{|lll|}
\hline & Mouflon $(\mathbf{n = 2})$ & Katahdin $(\mathbf{n = 4 )}$ \\
\hline Complex 'Attention', s & $246.5 \pm 31.85$ & $88.46 \pm 9.23$ \\
\hline Reaction-flehmen, s & $40.14 \pm 4.12$ & $45.93 \pm 4.08$ \\
\hline Intromission, s & $15.33 \pm 1.1$ & $2.3 \pm 0.1$ \\
\hline
\end{tabular}

\subsection{Sexual behavior of ewes}

The duration of estrus in ewes of different breeds, as well as in females of the same breed, can vary quite widely. Its length depends on the season, the age of the sheep, and the feeding and housing conditions. In the current study, the estrus in females lasted $19.9 \pm 1.3$ hours on average; the minimum value was 14 hours, and the maximum value was 26 hour. The ewes mated up to 25 times per day. As a rule, mounting happened in groups of 3-4 (up to 10) mountings that were several minutes apart; then, there would be a 1-2 hour break, followed by a new round of mating. Moreover, the length of the refractory period was largely variable and gradually increased when several acts of copulation happened in a row. In the first hours of estrus, the ewes were relatively inactive; they preferred not to move, and their heads were lowered. From about the fifth hour of estrus, the ewes' activity markedly grew. They insistently approached the ram, sniffed its head area and scrotum, struck an indicative pose, shook their heads from side to side, and watched the ram's courtship display (Fig. 5). It is during this period that ewes are most attractive to males and are susceptible to their courtship. The ram's persistent hits aimed at the groin area led to the ewe's urination. The average number of urinations by a ewe during the estrus period was $8-10$.

\subsection{Interrelation of ewes during the estrus period}

In addition to the interactions between the ewes and rams, we observed combinations of sexual behavior between ewes. The ewes not only jumped on other ewes during the rut, but also let them to jump on themselves; we also observed that females hit each other with their front legs and butted one another. Some ewes persistently interfered with the relationship of a ram with another ewe and sometimes completely disrupted their sexual behavior. Dominant ewes actively manifested a territorial behavior by 
driving lower-ranking ewes out of their beds. We also observed that lower-ranking sheep could not mate, despite the estrus condition. It should be noted that this behavior came into play and, accordingly, was observed by us when there was a subject to vie for; ewe in estrus did not demonstrate such behavior.

\section{Discussion}

As our observations have shown, in the European mouflon, most cases of mating occurred at night. For most of the day, the European mouflon showed a territorial and aggressive behavior, which was probably due to environmental factors, such as the presence of people and other animal species in the daytime. The existence of enclosures increases the aggressive behavior, even if there is sufficient space for habitation, as captivity increases interactions and encounters between animals [16]. The absence of a peak in the manifestation of reproductive behavior in purebred animals is probably due to domestication.

We observed attempts by the ewe to prevent other ewes from mating. As a rule, the demonstration of this behavior is intrinsic to social carnivorous mammals and has been found in wolves [17], African wild dogs, [18], and Asian badgers [19]. The manifestation of this behavior in sheep requires further observation in order to understand the occurrence of such patterns in ewes. Further studies have yet to find out whether competition for male sheep is caused by a high density of females per male or conditioned by individual hormonal states in some females. However, this certainly indicates the lability in the choice of sexual strategy in these animals.

Thus, we observed a very high overall variability in breeding strategies in domestic and wild sheep, with the patterns themselves being very similar. The choice of a particular mating system depends on the specific traits of an individual and its adaptability to differences in the social and ecological environment. The same has been observed for other animal species. Mating systems are more of reproductive strategies of individuals rather than the traits of species $[20,21]$. The high variability in breeding strategies is associated with high versatility in their social and spatial organization [22, 23, 24]. Complex social systems and diverse behavioral repertoires create both opportunities and challenges for behavioral biology. The animals have specific personal traits and regularly show signs of complex learning and retention abilities. In order to describe the breeding strategies of animals in detail and to understand how and why their breeding strategies actually change, it is necessary to conduct genetic studies as well as observations of the animals' behaviors. Therefore, the data presented in the present article are just the first step in describing the breeding process in circumstances of captivity, and further research is required.

\section{Conclusions}

The present study shows that the patterns of reproductive behavior in males of different species of sheep are similar. However, it was revealed that the species differ in the length of those patterns. A high variability in the strategies of sheep reproduction was observed. For future research, it would be beneficial to focus on the features of the reproductive behavior of female sheep depending on the genotype. 


\section{Declarations}

\section{Ethics Statement}

This study was conducted in accordance with the recommendations of the rules for the maintenance and care of farm animals (GOST-34088-2017) from 12 December 2017. The experimental protocols were approved by the Committee for the Care and Use of Animals of the Federal Research Center for Animal Husbandry named after L. K. Ernst (number 179 of 15.09.20).

\section{Consent for publication}

Not applicable.

\section{Availability of data and materials}

The datasets used and analysed during the current study are available from the corresponding author on reasonable request.

\section{Competing interests}

The authors declare that they have no competing interests.

\section{Funding}

This study was supported by the Ministry of Science and Higher Education of Russia (grant no. 04452021-0005).

\section{Author Contributions}

Conceptualization, B.I., N.K., and N.V.; methodology, B.I., N.K., N.V.and Y.P., ; software, B.I., N.K., and P.K.; validation, B.I., N.K., N.V.P.Y., and V.B; formal analysis, B.I., N.K., N.V.P.Y., and V.B.; writing-original draft preparation, B.I. and N.K.; writing-review and editing, B.I., N.K., N.V.Y.P.; visualization, B.I. and N.K. All authors have read and agreed to the published version of the manuscript.

\section{Acknowledgements}

Not applicable.

\section{References}

1. Trivers, R. L. "Parental investment and sexual selection,"inSexual Selection and the Descent of Man1871-1971, ed. B. Campbell (London, UK: Heinemann, 1972) 136-179.

2. Clutton-Brock, T. H. \& Parker, G. A. Potential reproductive rates and the operation of sexual selection.Quarterly Review of Biology67,437-456 (1992). 
3. Kappeler,P.M. Male Reproductive Strategies. Nature Education Knowledge,2012, 3(10):82

4. M. N. Erofeeva1; Naidenko, and S. V. Interspecific Variation in the Relationships of Mating Partners at Felids. Biol. Bull.2020, 58-66, doi:10.31857/S0002332919060067.

5. Osadchuk, L. V; Salomacheva, I.N.; Bragin, A. V; Osadchuk, A. V Maturation of Sexual Behavior in Laboratory Male Mice: A Role of Genotype. P. Pavlov J. High. Nerv. Act.2008, 58, 71-79.

6. Estienne, M.J. A review of the effects of prostaglandins on sexual behavior in boars. Anim. Behav. Sci. 2014, 154, 1-7.

7. L.S. Katz, T.J. McDonald. Sexual behavior of farm animals, Theriogenology,Volume 38, Issue 2,1992,Pages 239-253,https://doi.org/10.1016/0093-691X(92)90233-H.

8. Ostermann, S.D.; Deforge, J.R.; Daniel Edge, W. Captive Breeding and Reintroduction Evaluation Criteria: a Case Study of Peninsular Bighorn Sheep Reintroduction Evaluation Criteria Ostermann et al. Biol.2001, 15, 749-760.

9. Bazyan, S.; Asadi, H.; Rezaei, H.R.; Mesdaghi, M. Mating behaviour of wild sheep in captivity (Case study: Laristan Mouflon, Ovis orientalislaristanica). Garten2016, 85, 137-151, doi:10.1016/j.zoolgart.2015.11.001.

10. Rosa, H.J..; Bryant, M.. Seasonality of reproduction in sheep. Small Rumin. Res.2003, 48, 155-171, doi:10.1016/S0921-4488(03)00038-5.

11. El-Alamy, M.A.; Foote, R.H.; Hare, E. Sperm output and hormone concentrations in Finn and Dorset rams exposed to long- and short-day lighting. Theriogenology2001, 56, 839-54, doi:10.1016/s0093691x(01)00612-4.

12. Maina, D.; Katz, L.S. Scent of a Ewe: transmission of a social cue by conspecifics affects sexual performance in male sheep. Reprod.1999, 60,1373-7, doi:10.1095/biolreprod60.6.1373.

13. Preston, B.T.; Stevenson, I.R.; Wilson, K. Soay rams target reproductive activity towards promiscuous females' optimal insemination period. R. Soc. London. Ser. B Biol. Sci.2003, 270, 2073-2078, doi:10.1098/rspb.2003.2465.

14. M. M. Toishivekov, N. I. Akhmetova, B. R. Daminov, B. B. Molzhigitov, E.M.M. Hormonal stimulation of superovulation in the sheep. Proc. Natl. Acad. Sci. Repub. Kazakhstan2013, 6 (300), 44-48.

15. Nasibov, S.; lolchiev, B.; Klenovitskiy, P.; Bagirov, V.; Voevodin, V.; Zinov, N. Cryoconservation and rational use of genetic resources of sheep and goats. itekhniki APK2010, 9, 50-51.

16. Barkawi, A.H.; Elsayed, E.H.; Ashour, G.; Shehata, E. Seasonal changes in semen characteristics, hormonal profiles and testicular activity in Zaraibi goats. Small Rumin. Res.2006, 66, 209-213, doi:10.1016/j.smallrumres.2005.09.007.

17. Le Pendu, Y.; Guilhem, C.; Briedermann, L.; Maublanc, M.-L.; Gerard, J.-F. Interactions and associations between age and sex classes in mouflon sheep (Ovis gmelini) during winter. Processes2000, 52, 97107, doi:10.1016/s0376-6357(00)00129-7.

18. Isabel Soriano, A.; Vinyoles, D.; Maté, C. Inter-individual Distance in Different Captive Packs of Iberian Wolf (Canis lupus signatus): Management Applications. Appl. Anim. Welf. Sci.2020, 24, 1-11, 
doi:10.1080/10888705.2020.1790366.

19. Creel, S.; Creel, N.M. Communal hunting and pack size in African wild dogs, Lycaon pictus (vol 50, pg 1325, 1995). Behav.1995, 50, 1325-1339.

20. Rozhnov, V. V.; , N. V. Sidorchuk, M. N. Erofeeva, M.V.M. Reproductive behavior of the asian badger (MelesLeucurusAmurensis) at the ussurrsky reserve. J.2014, 93, 778-785, doi:10.7868/S0044513414060129.

21. Sundaresan, S.R.; Fischhoff, I.R.; Dushoff, J.; Rubenstein, D.I. Network metrics reveal differences in social organization between two fission-fusion species, Grevy's zebra and onager. Oecologia2007, 151, 140-9, doi:10.1007/s00442-006-0553-6.

22. Mario F Garcés-Restrepo, M Zachariah Peery, Brendan Reid, Jonathan N Pauli, Individual reproductive strategies shape the mating system of tree sloths, Journal of Mammalogy, Volume 98, Issue 5, 3 October 2017, Pages 1417-1425,https://doi.org/10.1093/jmammal/gyx094.

23. Avdi, M.; Banos, G.; Stefos, K.; Chemineau, P. Seasonal variation in testicular volume and sexual behavior of Chios and Serres rams. Theriogenology2004, 62, 275-282, doi:10.1016/j.theriogenology.2003.10.004.

24. De Fatima Damasceno Dos Santos, L.; Filho, E.C.P.; Saraiva, E.P.; Furtado, D.A.; Pereira, W.E.; Costa, J.H.S. Sexual behavior of "Morada Nova" breeding sheep under semiintensive rearing during the mating season in the brazilian semiarid. Semin. Agrar.2017, 38, 3657-3667, doi:10.5433/16790359.2017v38n6p3657.

\section{Figures}




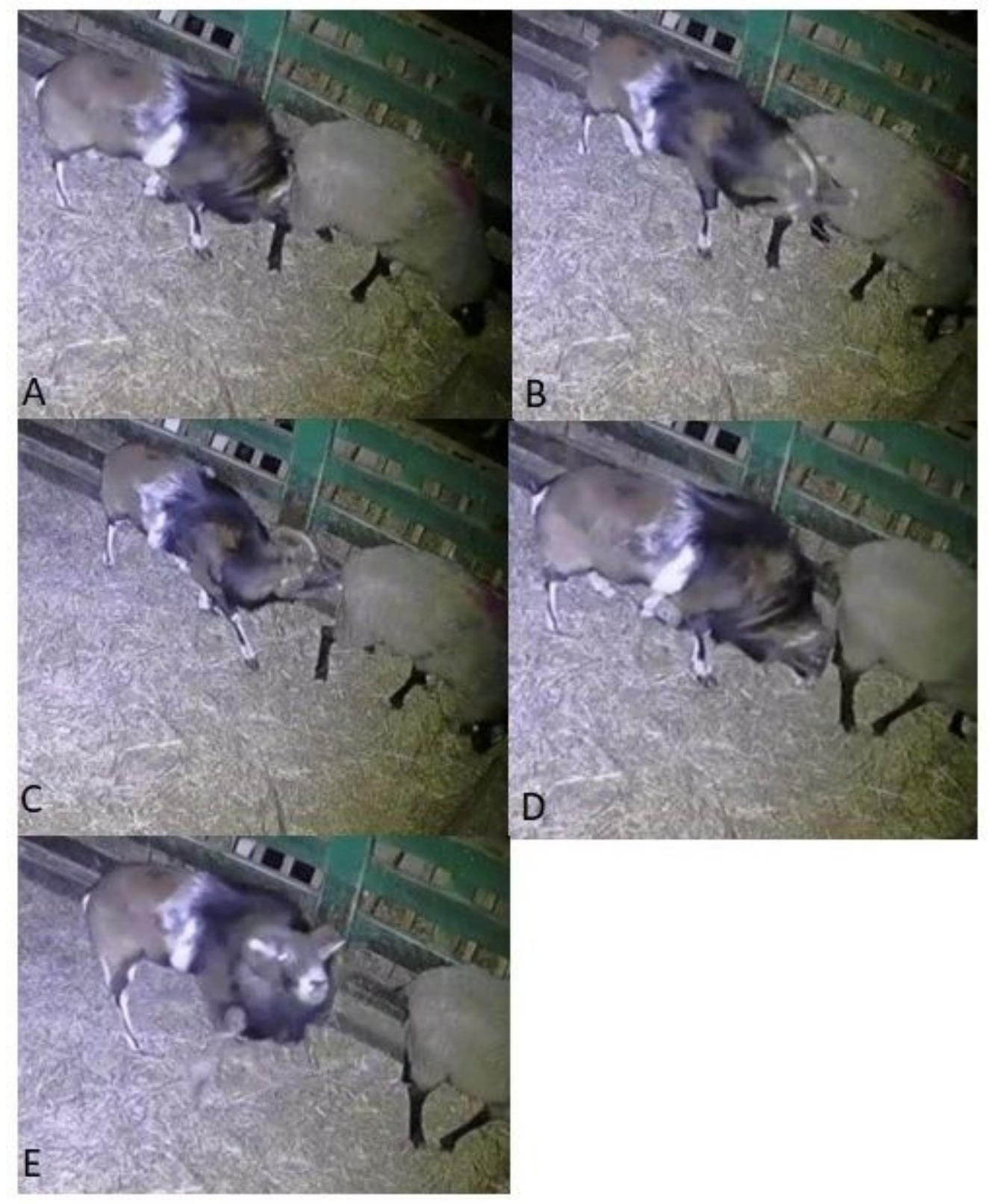

\section{Figure 1}

$A, B, C, D, E$. Photos of the chain of events observed in the European mouflon: sniffing and urination stimulation, straightening of the front limb, lowering of the head, and the flehmen reaction. 


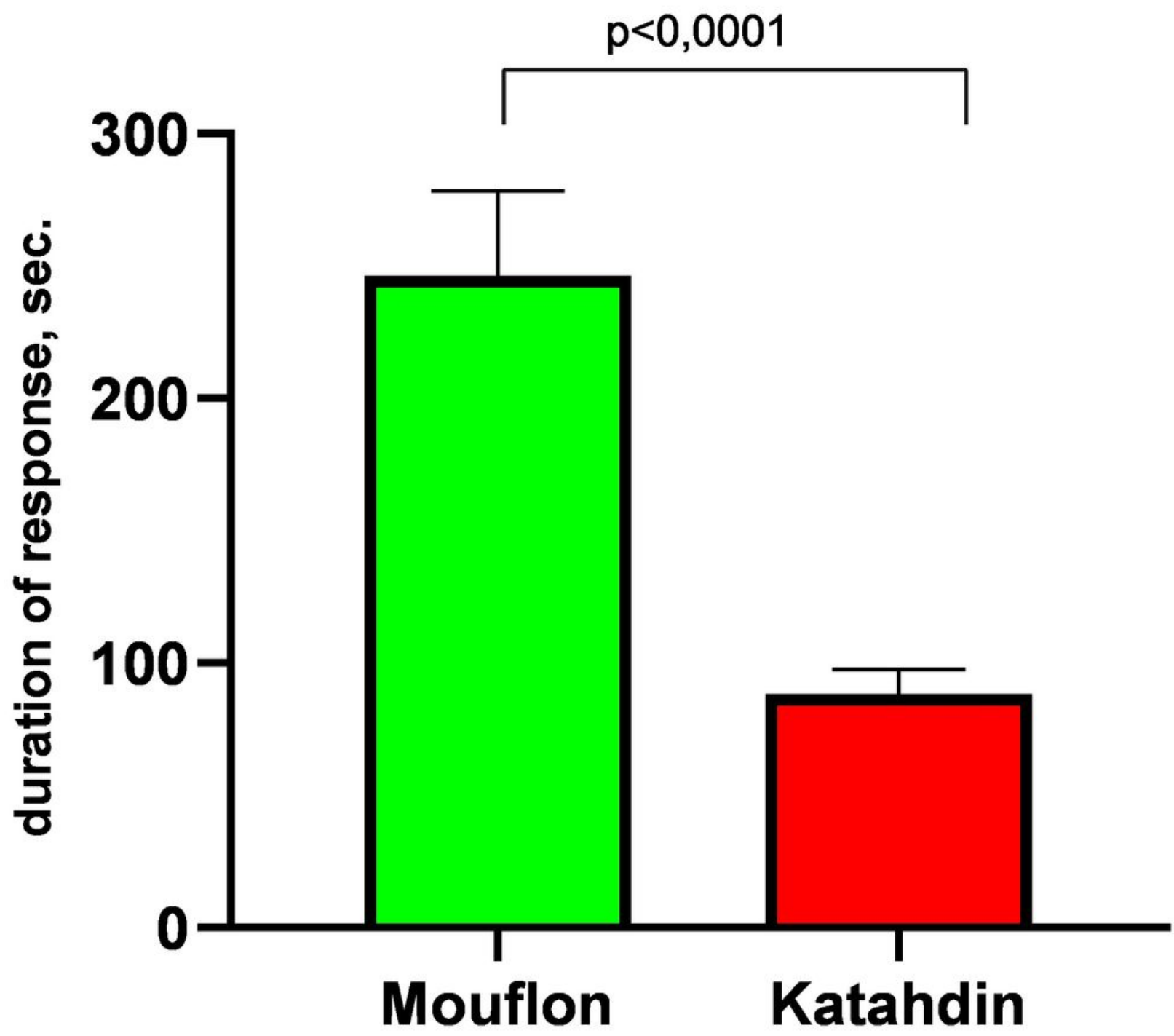

Figure 2

"Courtship" of males during the rutting period. 


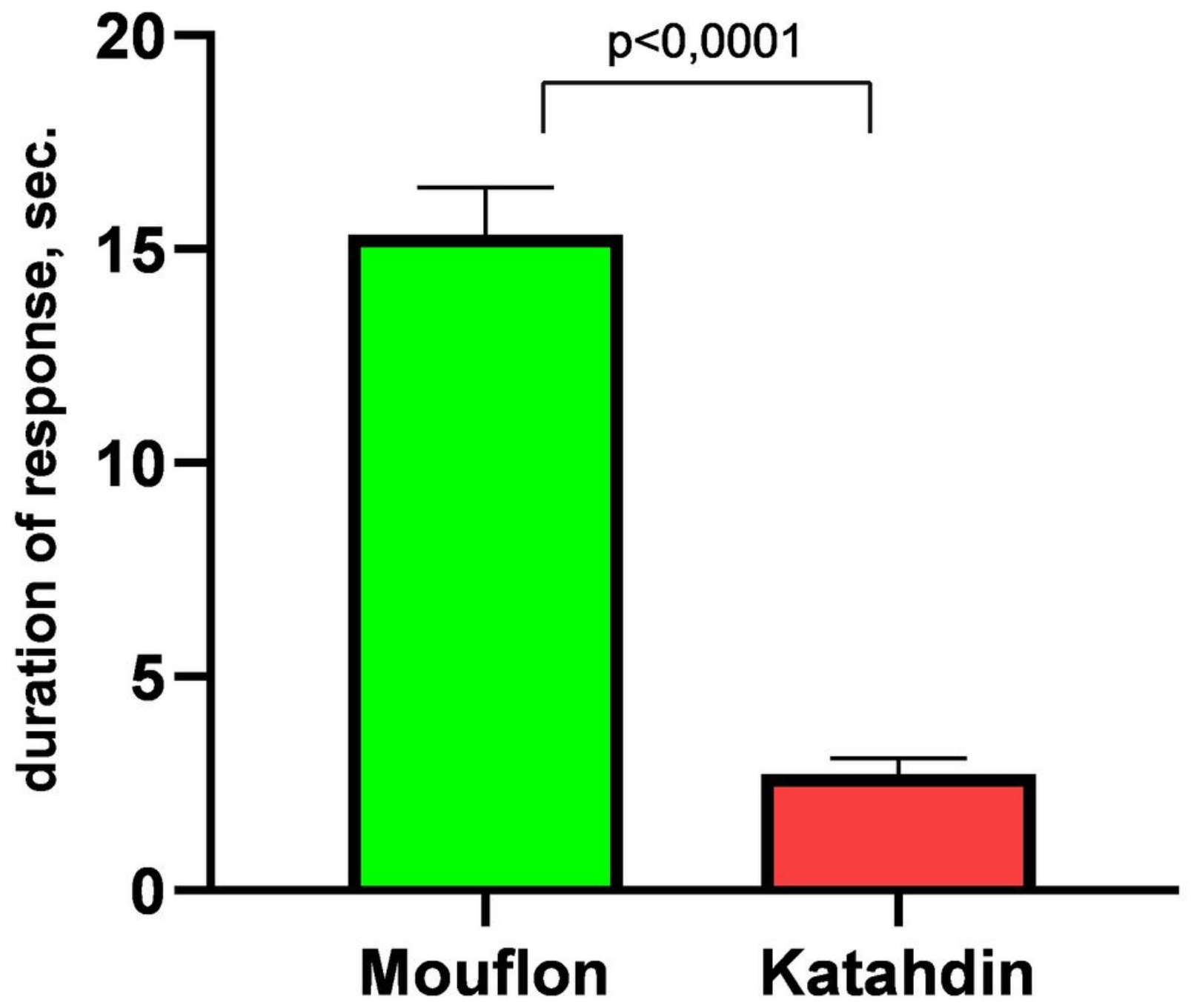

Figure 3

Intromission in rams. 


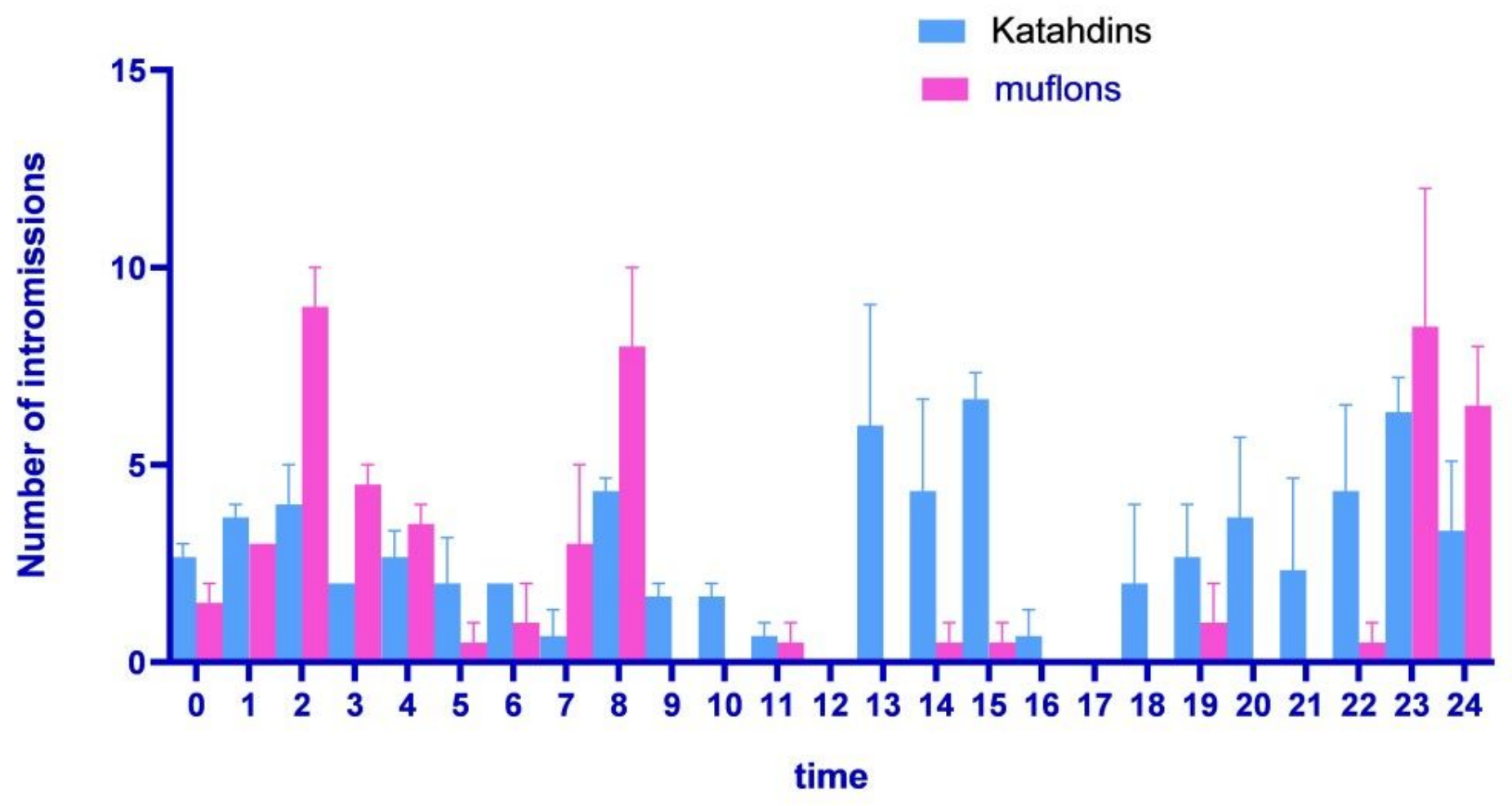

Figure 4

The number of intromissions depending on the time of day.

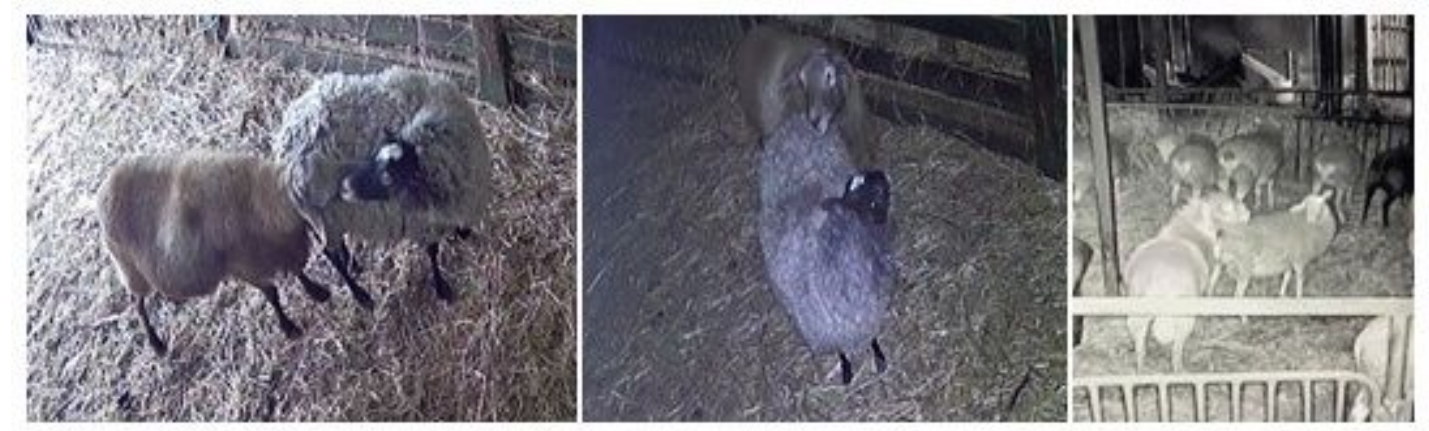

Figure 5

Photo of a sheep's typical posture during estrus. 